ernment, even if not by all its backbenchers). Though partly ideological, such support reflects the steady annual improvements in the NHS's effectiveness and safety seen in recent years. And third, turmoil provides an opportunity for innovation. It can produce collective efforts in which factional interests are set aside and long-standing controversial issues, such as bringing health care and social services closer together (even by combining their budgets into one), are finally addressed.

Although some of the challenges in England are unique, the underlying problem of meet- ing rising demand for care with steady or diminishing resources is faced by many countries. Just as we can learn from other health care systems, our experiences over the next few years in redesigning the organization and delivery of services will undoubtedly provide lessons for others.

Disclosure forms provided by the author are available with the full text of this article at NEJM.org.

From the Department of Health Services Research and Policy, London School of Hygiene and Tropical Medicine, London.

This article was published on June 19, 2013 , at NEJM.org.

1. Report of the Mid Staffordshire NHS
Foundation Trust public inquiry (Robert Francis, chair). Staffordshire, United Kingdom: Mid Staffordshire NHS Foundation Trust, February 2013.

2. Roberts A, Marshall L, Charlesworth A. A decade of austerity? The funding pressures facing the NHS from 2010/11 to 2021/22. London: Nuffield Trust, December 2012.

3. Black N, Mays N. Public inquiries into health care in the UK: a sound basis for policymaking? J Health Serv Res Policy 2013; 18:129-30.

4. Rating providers for quality: a policy worth pursuing? London: Nuffield Trust, March 2013.

5. Shahian DM, Wolf RE, lezzoni LI, Kirle L, Normand S-LT. Variability in the measurement of hospital-wide mortality rates. N Engl J Med 2010;363:2530-9. [Erratum, N Engl J Med 2011;364:1382.]

DOI: 10.1056/NEJMp1305771

Copyright @ 2013 Massachusetts Medical Society.

\title{
NICE: Moving Onward
}

\author{
Michael D. Rawlins, M.D.
}

T he National Institute for Clinical Excellence (NICE) was established in 1999, primarily to offer professionals in Britain's National Health Service (NHS) advice on providing care that meets the highest attainable standards. NICE's role was expanded in 2005 to include provision of analogous advice to the broader public health community on preventing ill health and maintaining good health. (The name was changed to the National Institute for Health and Clinical Excellence, but the acronym NICE has continued to be used.)

To meet these objectives, NICE now has three different strands of responsibilities (see table), ${ }^{1}$ and its budget from the government has increased tenfold. Much attention, however, continues to focus on NICE's technology appraisals and clinical-guideline programs.

Since 2000, the Institute has been publishing technology appraisals - assessments of the clinical effectiveness and costeffectiveness of (mainly) new pharmaceutical products, including whether providing them constitutes a good use of NHS resources. Contrary to popular mythology, NICE rejects less than $15 \%$ of technologies on the grounds of cost-ineffectiveness. In recent years, manufacturers have increasingly been offering the NHS, through NICE, "patient access schemes," which can substantially reduce the price of products and render them more likely to be considered cost-effective. Such offers have sometimes led a product with a negative provisional assessment to gain a positive final one, and occasionally decisions have been reversed because manufacturers have submitted additional evidence about a product's clinical effectiveness.

NICE's clinical guidelines improve the quality of care provided to NHS patients. For example, after the publication of a guide- line on the prophylactic use of antibiotics in patients with mechanical cardiac lesions, the volume of prescriptions by dental surgeons fell by more than $80 \%$ in 6 months. ${ }^{2}$ Similarly, as a result of a guideline on preventing venous thromboembolism, the rate of risk assessments in patients admitted to NHS hospitals increased from less than $40 \%$ in 2010 to $94 \%$ in 2012. ${ }^{3}$ Not all NICE's clinical guidelines have had such an effect: the Institute's guidance on managing infertility, including the use of in vitro fertilization, was fully adopted by only about $25 \%$ of primary care trusts (the regional administrative bodies that, until recently, commissioned and provided health care services to NHS patients).

NICE distinguishes clinical guidelines defining optimal care pathways for specific conditions from standards describing generic competencies for health care professionals. Professional standards 


\section{Guidance programs}

Technology appraisals

Clinical guidelines

Interventional procedures

Public health

Medical technologies

Diagnostic agents

Performance standards and metrics

Quality Outcomes Framework

Quality standards

Clinical Commissioning Group

Outcome Indicators

Information services

NHS Evidence

NICE Pathways

Medicines Management
Decisions about use of mainly new health technologies in the National Health Service (NHS) based on their clinical effectiveness and cost-effectiveness

Advice on management of specific clinical conditions based on clinical effectiveness and cost-effectiveness

Determinations of whether mainly new interventional procedures are sufficiently safe and effective for use in the NHS

Guidance about disease prevention, health improvement, and health protection for both the NHS and local government

Decisions about use of cost-saving medical technologies in the NHS

Decisions about use of mainly new in vivo and imaging methods in the NHS based on clinical effectiveness and cost-effectiveness

Menu of clinical indicators for inclusion in the NHS contract with family doctors

Key performance indicators in specific areas to which a high-performing institution should aspire

Key indicators for measuring health outcomes for services commissioned mainly by professional groups (predominantly comprising general practitioners) called Clinical Commissioning Groups

Online search engine identifying reliable sources of material relevant to a particular clinical problem

Totality of NICE guidance, in algorithmic form, about a particular topic or condition (available as apps for iPhones, iPads, and Android devices)

Evidence summaries for new medicines not undergoing technology appraisal

Evidence regarding unlicensed and off-label use that is not included in a guideline

Good practice advice (e.g., on the construction of local hospital formularies) may cover anything from treating patients with dignity and respect, to ways of avoiding bedsores, to the procedure for safely inserting a nasogastric tube. These standards are generally agreed to be the responsibility of the medical and nursing regulatory authorities, the royal colleges and professional societies. The recent scandal at Mid-Staffordshire Hospitals - where investigators found what were widely described as "appalling" conditions and care - was primarily attributable to failures in adhering to professional standards. ${ }^{4}$

I believe that NICE has largely succeeded in its mission, thanks to four key ingredients. The first has been the political and fiscal environment. There is now wide acceptance that no country seeking to provide universal health care has the resources necessary to achieve the highest possible standards of care for everyone.
In 1999, when NICE was established, there was limited, tacit acceptance of this gloomy fact. Fourteen years later, there is greater honesty among politicians and health policymakers, owing in part to the global financial crisis. Priorities must be set on the basis of evidence of both clinical effectiveness and cost-effectiveness.

However, priority setting in health care must encompass more than the technical and scientific demands of health technology assessment. It must also take account of the social values of the relevant communities. NICE therefore established a Citizens Council, with members drawn from the general public, to examine, deliberate over, and report on the social principles on which the Institute's guidance should be based. ${ }^{5}$ Health care systems elsewhere need to develop their own approaches to eliciting social values, which won't necessarily re- flect the culture and preferences of the British public.

Second, NICE has adopted a methodologically rigorous approach to guidance development. All NICE guidance is based on a full systematic review of the available evidence, including not only the results of randomized, controlled trials, but also observational and analytic studies. Information on the Institute's processes and methods is publicly available, and these processes undergo revisions every 3 years. The World Health Organization has reviewed them twice and found, overall, that NICE guidance is developed to the highest standards.

The third factor is inclusivity. The Institute has strived to involve its stakeholders - health care professionals, patients and their representative organizations, and relevant life-sciences companies - in all its programs. All 
stakeholders are invited to contribute to revisions of our processes and methods and encouraged to submit evidence on particular topics for consideration by the Institute's advisory bodies.

All NICE's clinical-guideline groups include at least two patients (or "service users"), except in the case of guidelines for children's illnesses, in which we include the parents of children with the condition in question. Because meeting with distinguished clinicians can be daunting, NICE provides participating service users with specific training for their role.

The Institute's stakeholders have been generally (though not uncritically) supportive. Despite a rocky beginning with the lifesciences industry and particularly the pharmaceutical industry, relations improved as it became clear that we supported the use of most new drugs but that health care systems globally can afford only cost-effective products.

Fourth, NICE has, from the outset, jealously guarded its independence from vested interests, whether government, the professions, patient organizations, or the life-sciences industries. Government ministers formally refer specific appraisal, clinical-guideline, and public health topics to the Institute for development. At first, Department of Health officials selected topics for approval by government ministers, but now NICE proposes topics for referral by ministers, and then guidance con- tent becomes entirely the responsibility of the Institute and the relevant advisory body. Ministers do not attempt to influence NICE guidance and have never threatened to overturn any of NICE's advice.

All NICE guidance is developed by independent members of advisory bodies, who are drawn from the NHS and British universities. The Institute's board can suppress a piece of guidance that it believes to be flawed, but it has never had to exercise this option. From the outset, the Institute has had strict conflict-of-interest rules covering both its staff and advisory-body members.

NICE is now a permanent component of the British health care environment, having been reestablished on April 1, 2013, in legislation that also requires the Institute to develop guidelines and performance metrics for social services. This change, I hope, will help improve the integration of Britain's health care and social services, whose interactions have too often been dysfunctional. (With this addition to its remit, the Institute's name has been changed again, to the National Institute for Health and Care Excellence.)

NICE's experience may carry lessons for the United States, which has an abundance of the technical, scientific, and clinical skills needed to develop robust guidance for clinical practice but which appears, at least to an outsider, to lack the political will to ensure the provision of universal health care and to accept that in so doing it will have to set priorities. The Affordable Care Act takes a modest step in this direction, but the current level of expenditure on health care in the United States is unsustainable. If the United States is to meet the needs of all its citizens, especially in the face of an increasingly elderly population, it will someday have to take both clinical effectiveness and cost-effectiveness into account in determining the contents of its package of universal health care. Our experience in the United Kingdom shows that, though sometimes uncomfortable, it is possible.

Disclosure forms provided by the author are available with the full text of this article at NEJM.org.

From the Royal Society of Medicine and the London School of Hygiene and Tropical Medicine - both in London. Dr. Rawlins was chairman of NICE from April 1999 to April 2013.

1. Rawlins MD, Dillon A, Leng G. What's happening at NICE? Clin Med 2013;13:13-5.

2. Thornhill MH, Dayer MY, Forde JM, et al. Impact on the NICE guideline recommending cessation of antibiotic prophylaxis for prevention of infective endocarditis: before and after study. BMJ 2011;342:d2392.

3. VTE Risk Assessment data collection: October to December 2012. London: Department of Health (http://www.transparency .dh.gov.uk/2013/03/01/vte-q3-2012-13).

4. Francis R. Report of the Mid Staffordshire NHS Foundation Trust public inquiry. London: The Stationery Office, 2013 (http://www .midstaffspublicinquiry.com/sites/default/ files/report/Executive\%20summary.pdf).

5. Littlejohns P, Rawlins M, eds. Patients, the public and priorities in healthcare. Abingdon, United Kingdom: Radcliffe, 2009.

DOI: 10.1056/NEJMP1303907

Copyright (C) 2013 Massachusetts Medical Society.

\section{From Imaging Gatekeeper to Service Provider A Transatlantic Journey}

Saurabh Jha, M.B., B.S.

$\mathrm{n}$ Britain, where I trained in surgery, residents feared radiologists. One radiologist was nick- named "Dr. No," since his first response was always to deny requests for any imaging other than a plain radiograph. We had no computerized order-entry system, so after rounds, the junior 